\title{
Sobering Stories: Narratives of Self-Redemption Predict Behavioral Change and Improved Health Among Recovering Alcoholics
}

\author{
William L. Dunlop and Jessica L. Tracy \\ University of British Columbia
}

\begin{abstract}
The present research examined whether the production of a narrative containing self-redemption (wherein the narrator describes a positive personality change following a negative experience) predicts positive behavioral change. In Study 1, we compared the narratives of alcoholics who had maintained their sobriety for over 4 years with those of alcoholics who had been sober 6 months or less. When describing their last drink, the former were significantly more likely to produce a narrative containing self-redemption than the latter. In Study 2, we examined the relation between the profession of self-redemption and behavioral change using a longitudinal design, by following the newly sober alcoholics from Study 1 over time. Although indistinguishable at initial assessment, newly sober alcoholics whose narratives included self-redemption were substantially more likely to maintain sobriety in the following months, compared to newly sober alcoholics who produced nonredemptive narratives; $83 \%$ of the redemptive group maintained sobriety between assessments, compared to $44 \%$ of nonredemptive participants. Redemptive participants in Study 2 also demonstrated improved health relative to the nonredemptive group. In both studies, the effects of self-redemption on sobriety and health held after controlling for relevant personality traits, alcohol dependence, recovery program involvement, initial physical and mental health, and additional narrative themes. Collectively, these results suggest that the production of a self-redemptive narrative may stimulate prolonged behavioral change and thus indicate a potentially modifiable psychological process that exhibits a major influence on recovery from addiction.
\end{abstract}

Keywords: redemption, narrative identity, alcoholism, behavioral change, psychological health

Humans are natural storytellers (Bruner, 1990). They construct stories to bring a sense of comprehension and coherence to the events around them. In the same vein, they construct life stories to bring comprehension and coherence to their lives (McAdams, 2001). In the past 30 years, the life story has received a substantial amount of research attention from psychologists across disciplines, including personality (e.g., McAdams, Reynolds, Lewis, Patten, \& Bowman, 2001), social (e.g., Baumeister, Stillwell, \& Wotman, 1990), clinical (e.g., Singer, 1997), cognitive (e.g., Conway, 2005), and developmental (e.g., McLean, 2008) researchers (Adler, 2012). These investigators have contributed to our understanding of many features of the life story, including how it is used to justify

William L. Dunlop and Jessica L. Tracy, Department of Psychology, University of British Columbia, Vancouver, British Columbia, Canada.

The authors are grateful for the support of a Michael Smith Foundation for Health Research Scholar Award and Establishment Grant and a Canadian Institute for Health Research New Investigator Award and Operating Grant to the second author as well as a graduate scholarship from the Social Sciences and Research Council of Canada to the first author. We thank Dana Dmytro and Amine Bouzaher for their research assistance as well as members of the UBC Emotion and Self research group for their scholarly comments and critiques on an earlier version of this article.

Correspondence concerning this article should be addressed to William L. Dunlop, Department of Psychology, University of British Columbia, Douglas Kenny Building, 2136 West Mall, Vancouver, British Columbia V6T 1Z4, Canada. E-mail: wdunlop@psych.ubc.ca individuals' own behavior and the behavior of others (e.g., Baumeister et al., 1990; Pasupathi \& Wainryb, 2010), its development through adolescence and young adulthood (e.g., Bohn \& Berntsen, 2008; Habermas \& Bluck, 2000), and its correspondence with psychological adjustment (e.g., Bauer, McAdams, \& Sakaeda, 2005; McAdams et al., 2001).

In recent years, there has been a shift in narrative research, toward the examination of how life stories influence certain life outcomes, most notably psychological adjustment (Adler, 2012). This transition is consistent with McAdams's (1985, 1993) original conception of the life story as functional, serving, in essence, as the "story we live by" (McAdams, 1985, 1993). From this perspective, once a narrative about one's past is constructed, an individual feels compelled to maintain congruence with this self-defining story or, in Giddens's (1991) words, to "keep a particular narrative going" (p. 54). Interestingly, if this is the case-that personal narratives are developed for the purpose of providing direction to one's life-then for those who create a story that professes positive or adaptive self-change following a negative or harrowing experience (i.e., redemption), the life story may function to promote not consistency in one's behaviors but, rather, change. In other words, those who construct redemptive stories may be motivated to change their behaviors to align with the bettered self-image that is described. As a result, upon constructing a story in which a bettered self emerges following adversity, narrators may actually become better, in part by reducing their engagement in problematic behaviors. However, despite considerable theoretical support for this assumption (e.g., Giddens, 1991; McAdams, 1985; Wilson, 
2002), few researchers have examined the correspondence between the narration of a positive personal transformation and behavioral change. Indeed, we are unaware of any previous research that has directly tested whether the narration of personal growth stimulated by a negative experience predicts subsequent life changes consistent with the story told.

To address this gap in the literature, we investigated the relation between the narration of a positive self-transformation following a difficult experience and behavioral change, and we did so by examining stories and behaviors among a unique sample of individuals for whom these issues are likely to be particularly relevant, as they are seeking (or have sought) to dramatically change and improve their lives: recovering alcoholics. These individuals represent an ideal population within which to test this relation, both because they are, by definition, actively seeking to change their lives and behaviors in a fundamental way, and because many self-help addiction recovery programs (e.g., Alcoholics Anonymous [AA]) encourage recovering addicts to develop coherent personal narratives about their addiction that climax with a positive personal transformation and successful recovery (Denzin, 2009; O'Reilly, 1997). Although as yet empirically untested, a core assumption implicit in this institutionalized emphasis is that addicts' behaviors will come to align with the narrative plot of the personal stories they create; that once a story detailing personal growth following abstinence is constructed, the story will come to influence the narrator, thereby stimulating the recovery process.

In the present research, we asked alcoholics who were members of AA to construct and narrate a story regarding a (potentially) critical moment in their lives - their last drink. In the minds of some, this drink represents the turning point at which commitment to sobriety is renewed, character is improved, and recovery is stimulated. In the minds of others, however, this drink simply represents the most recent lapse, one soon to be followed by a long line of others. Drawing on the theoretical work outlined above (e.g., Giddens, 1991; McAdams, 1985), we predicted that individuals who narrated stories depicting personal improvement following their last drink would exhibit a change in behavior consistent with this description (i.e., extended sobriety, improved general health), relative to those whose narratives did not reflect a sense of positive self-change.

\section{The Life Story, Redemption, and Psychological Functioning}

The life story is a narrative representation of one's past, present, and anticipated future (McAdams et al., 2001). Through its creation, individuals work to synthesize the many experiences they have amassed, and foresee amassing, into a unified, coherent, and compelling whole. This is typically done in the interest of fostering self-understanding and personal meaning. The life story, therefore, represents a psychosocial construction that facilitates the attainment of a narrative identity (Adler, 2012; McAdams, 2001; Singer, 2004).

Life stories differ in the degree to which they contain themes of redemption, which is identified when a negative experience is described as leading to a positive outcome (see McAdams, 2006). Just as the motivation to create a life story derives in part from a desire to imbue one's life with meaning, so too does the motivation to create a redemptive narrative derive in part from a desire to make sense of harrowing past experiences (McAdams, 2006; Pals $\&$ McAdams, 2004). Put differently, by coming to view a difficult life experience as having led to something positive or good, this experience may become easier to comprehend (King, 2001). In line with this notion, several researchers have suggested a correspondence between framing difficult life experiences in a redemptive manner and psychological adjustment (McAdams, 2006; McAdams et al., 2001).

\section{Redemptive Narratives and Psychological Adjustment}

Within the stress and coping literature, a number of studies have shown that, when individuals perceive benefits (be they social, relational, or personal in nature) from the adversities they experienced, they tend to exhibit a heightened level of adjustment relative to those who do not perceive such benefits. For example, Davis, Nolen-Hoeksema, and Larson (1998) found that recently bereaved participants who perceived some benefit from the death of a close other exhibited a reduced level of distress relative to those who did not perceive such a benefit. This relation was observed irrespective of whether the benefit was reported shortly after the death of a loved one or during the following year. Similarly, Carver and Antoni (2004) found that cancer patients who perceived a benefit from their illness evinced less negative affect compared to patients who did not believe that their illness was in some sense beneficial. The association between the perception of benefit and increased psychological adjustment has in fact been observed following a number of traumatic events, including heart attacks (Affleck, Tennen, Croog, \& Levine, 1987), hostage attempts (Cole, 1992), and child abuse (e.g., McMillen, Zuravin, \& Rideout, 1995).

The aforementioned results suggest that perceiving benefit in life's hardships may provide certain psychological advantages. However, these findings do not specifically address whether the construction of a redemptive narrative corresponds with psychological adjustment - that is, whether the process of telling one's life story in such a way as to indicate a sense of redemption might itself be associated with health-related life outcomes. In research more directly addressing this issue (e.g., Bauer et al., 2005; Lilgendahl \& McAdams, 2011; McAdams et al., 2001), a positive relation has been observed between the tendency to narrate one's personal experiences in redemptive terms and psychological wellbeing. Assessing the life stories of young and middle-aged adults, McAdams et al. (2001) found that narrated redemption was positively related to life satisfaction, self-esteem, and eudaemonic well-being and negatively related to depression. Adler and Poulin (2009) built upon and extended these results by demonstrating a negative correspondence between redemptive themes in personal stories regarding a national tragedy and psychological distress. More recently, Lilgendahl and McAdams (2011) found that producing a narrative containing the profession of self-growth was positively related to psychological well-being. Importantly, the predictive ability of this narrative theme remained significant after controlling for personality traits and demographic information that might contribute to both well-being and the tendency to produce a redemptive narrative.

The results of Lilgendahl and McAdams (2011) suggest that the relation between the narrative construal of personal improvement and psychological adjustment may be independent of other ele- 
ments of the person. Furthermore, research by Pals (2006) has suggested that the relation between professions of self-development and adjustment also may be independent of other elements of the narrative in question. Specifically, Pals found that narratives containing self-growth positively predicted ego maturity, life satisfaction, and physical health and that these relations could not be accounted for by other features of the narratives (e.g., exploratory narrative processing), suggesting that this flavor of redemption, in particular, may be a critical factor underlying the relation between one's life narrative and positive life outcomes.

\section{Redemptive Narratives and Behavioral Patterns}

In addition to considering the relation between redemption and psychological health, several research groups (e.g., Matsuba \& Walker, 2005; McAdams, Diamond, de St. Aubin, \& Mansfield, 1997; McAdams et al., 2001; Walker \& Frimer, 2007; Walker, Frimer, \& Dunlop, 2010) have examined associations between the tendency to describe one's life in redemptive terms and prosocial, or generative, behaviors. This research has been largely informed by Tomkins's (1987) notion of the commitment script, which views redemption as a key constituent helping to "bind the person to a long-term activity" (p. 167).

In a study contrasting the life stories of highly generative individuals (identified on the basis of their excellence in teaching or volunteer work within the community) with a less generative sample, McAdams et al. (1997) found that generative participants were more likely to frame their major life events redemptively. Similarly, Walker and Frimer (2007) and Walker et al. (2010) noted that individuals who had been nationally recognized for a brave (and dangerous) behavior or a long-term pattern of volunteerism demonstrated higher levels of redemption in their life stories compared to less prosocial individuals.

Written professions of self-change and/or redemption have also been examined in relation to changes in personality traits (e.g., Lodi-Smith, Geise, Roberts, \& Robins, 2009). Lodi-Smith et al. (2009) recruited a sample of young adults in their first year of college to complete a personality inventory. Three years later, these students again completed this inventory and provided a written narrative describing how they had changed since entering college. The degree to which participants' narratives contained professions of self-change and redemption was found to positively predict increases in conscientiousness, suggesting that these narratives are related to personality change. However, because narratives were assessed during the second wave, after any personality change had occurred, these findings do not indicate whether these narrative themes precede or follow the aforementioned changes. Furthermore, because these results speak broadly to the relation between self-narrative and personality change, they do not indicate whether redemption, in particular, is related to the mitigation of problematic behavioral patterns, in particular.

\section{Redemptive Narratives and Behavioral Change}

From a theoretical perspective, it is intuitive that framing a difficult experience as a springboard for personal development or improvement would carry positive downstream consequences, particularly in the domain of behavioral change. As Giddens (1991) noted, individuals generally seek to maintain consistency with the stories they construct (see also McAdams, 1985; McAdams \& Pals, 2006). It follows then, that if one's story includes a positive transformation or personal improvement in the wake of a traumatic or negative experience, the narrator may work to align his or her subsequent behaviors with this bettered self-image. In this respect, the construction of a personal story in which the self is redeemed may play an important role in the mitigation of problematic behaviors. To be sure, the profession of a positive personal transformation represents but one way in which an individual might describe a negative experience as leading to a beneficial outcome. Indeed, individuals often "redeem" experiences by perceiving an improvement in their social conditions or personal relations, rather than in their sense of self (Tedeschi \& Calhoun, 1996). Here we distinguish between redemption broadly construed and redemption pertaining to improvement in the self, specifically, by referring to the latter as self-redemption.

Alcohol addiction is one domain in which the construction of a story containing self-redemption has been deemed particularly relevant (Diamond, 2001). Surveying the personal stories of a group of alcoholics who had repeatedly failed to maintain sobriety, Singer (1997) observed that these individuals tended to struggle when tasked with authoring a redemptive personal story. Similarly, in his psychobiography of George W. Bush, McAdams (2011) proposed that the formation of a redemptive life story may have played a role in Bush's recovery from alcohol addiction. Furthermore, in small-scale qualitative investigations of alcohol recovery programs such as AA, researchers have noted an emphasis on the construction of stories that are redemptive, in which the self and one's life improve following sobriety (e.g., Denzin, 2009; O'Reilly, 1997).

Indeed, the emphasis on striving for self-redemption is particularly apparent within AA, a self-help alcohol recovery organization boasting over 2 million members worldwide. This focus on positive transformation in the wake of alcohol addiction is manifest in the organization's official guidebook (Alcoholics Anonymous World Services, 2004), which includes a collection of transformative life stories written by its members. This emphasis is also manifest in AA's regularly held speaker meetings, at which members are encouraged to share their experiences pertaining to alcohol and addiction, and professions of self-redemption from consistently abstinent members tend to be particularly well received (Denzin, 2009). Indeed, it has been proposed that the purpose of these meetings is to reward and foster such stories, leading O'Reilly (1997) to assert that "there is really only one story in AA" (p. 24).

One prior cross-sectional study, which compared the stories of reformed and nonreformed criminals, provides some preliminary empirical support for AA's emphasis on narratives containing a positive personal transformation following harrowing experiences. When contrasting the life stories of reformed criminals with those who had yet to desist, Maruna (2001) observed that reformed participants were much more likely to produce redemptive sequences in their life stories. Interpreting this finding, this researcher suggested that criminals may need to adopt a redemptive story in order to achieve desistence, for both personal and social reasons. At a personal level, constructing a story describing selfimprovement makes possible the reconciliation of a sordid past with a crime-free future. That is, the exposition of self-redemption allows the narrator to maintain a sense of self-continuity or per- 
sonal persistence in the face of drastic personal change (Chandler, Lalonde, Sokol, \& Hallett, 2003). At a social level, a story containing self-redemption may be necessary to convince others that one has actually rehabilitated. Indeed, if former criminals fail to provide a story with a precipitous incline, others may "simply not 'buy' a person's claims to being reformed" (Maruna, 2001, p. 86). These two features are likely relevant to the potential benefits experienced by AA members who tell redemptive stories as well. In both cases, the narration of self-redemption is viewed as a precursor to desistence, and the telling of the story is highly social, as it must be told to and accepted by others in the individual's community.

\section{Previous Research on Redemption and Change in Behavior or Life Outcomes}

Despite the insights gained from prior research on redemptive narratives, a number of important questions remain. First, in prior studies narratives have almost invariably been assessed following the production of the corresponding behavior of interest (i.e., generativity, recidivism), or at the same time as the assessment of certain life outcomes (e.g., psychological adjustment; but see Adler, 2012). As a result, these studies do not allow us to determine whether self-redemption precedes - and thus potentially contributes to-the given behavioral change and/or life outcome, or whether the behavior precedes (and potentially contributes to) the construction of a narrative containing professions of a positive transformation, as certain theories of self-knowledge would suggest (e.g., Bem, 1972; Nisbett \& Wilson, 1977). Second, redemption has most commonly been assessed by determining its frequency across a host of different kinds of narratives (e.g., high points, low points, turning points) embedded within a broader life story. For this reason, we currently do not know whether the redemptive construal of a specific low point or traumatic experience might influence changes in behavior and life outcomes relevant to that experience. Finally, in the majority of research on redemption, participants have been encouraged to discuss any life events they would like (e.g., death of a parent, end of romantic relationship). Although this approach allows for the collection of valuable information regarding the most significant moments in participants' lives, the consideration of stories that vary across participants complicates the examination of specific narrative processes associated with adjustment or personality development (King, Scollon, Ramsey, \& Williams, 2000). For these reasons, general claims regarding the nature of redemption and behavioral change (e.g., Pals \& McAdams, 2004) and specific claims regarding self-redemption and recovery from alcohol addiction (e.g., Diamond, 2001) remain largely untested. Indeed, although a recent study used a longitudinal approach to examine the relation between changes in the narratives of psychotherapy clients and changes in mental health (Adler, 2012), this research did not examine behavioral change (mental health was assessed via selfreport), leaving open the question of whether narrative themes in fact influence subsequent behaviors.

\section{The Present Research}

The goal of the present research was to determine whether the production of a narrative regarding a difficult life event that contains themes of self-redemption predicts behavioral change and improved health. To achieve this goal, we examined whether alcoholics' tendency to perceive a sense of self-redemption while telling the story of their most recent drink was associated with a corresponding recovery trajectory, and we did so using both a cross-sectional and longitudinal design. We chose to examine alcoholics' stories about their last drink because, as King et al. (2000) noted, keeping standard the event in question better allows for the examination of the effects of particular narrative themes. Furthermore, we refrained from explicitly asking participants to narrate this event in redemptive terms, because we hoped to capture individual differences in the tendency to spontaneously redeem (vs. not redeem) one's past addictive drinking. For this reason, we also did not prompt participants to describe an experience of "bottoming out," or a "turning point" (see McAdams, 2001), both of which might motivate individuals to frame their narratives in redemptive terms, and thereby reduce our ability to test whether the unprompted description of redemption in one's narrative about the last drink influences recovery outcomes.

In Study 1, we compared the prevalence of professions of self-redemption among alcoholics who had maintained their sobriety for over 4 years with the prevalence of such professions among newly sober alcoholics who had maintained their sobriety for 6 months or less. We hypothesized that if the production of narratives containing self-redemption is a principal factor underlying successful behavioral change, then individuals who had maintained their sobriety for a significant period would be more likely to describe their last drink as leading to self-redemption than newly sober individuals. In Study 2, we tested whether newly sober alcoholics' production of a self-redemptive narrative would correspond with their subsequent recovery trajectories over the course of 4 months. We predicted that those who professed selfredemption would be more likely to maintain sobriety months later, and would exhibit greater improvements in general health, relative to those whose prior narratives did not evince such themes.

It is important to note that individuals who ultimately recover from alcohol addiction typically differ from those who do not on numerous personality and demographic factors, and that narratives containing self-redemption tend to differ in multiple ways from narratives without this theme (Dunlop \& Tracy, 2012). With respect to the former concern, demographic variables such as age, as well as personality characteristics such as optimism, dispositional positive and negative affect, depression, anxiety, attributional style, alcohol dependence, and recovery program involvement have been found to predict the likelihood of successfully recovering from alcohol addiction (Carver, Scheier, \& Segerstorm, 2010; Dawson et al., 2005; Dowd, Lawson, \& Petosa, 1986; Moos \& Moos, 2006; Willinger et al., 2002). With respect to the latter, the microanalytic content of narratives (i.e., specific words and terms) has been found to relate to subsequent health-relevant behaviors and psychological adjustment (Pennebaker \& Chung, 2011). In their review of research in this area, Pennebaker and Chung (2011) identified a handful of specific narrative elements (e.g., the percentage of positive emotion words, causal words) that are particularly pertinent to these behaviors and life outcomes.

In our examination of the relation between self-redemption and behavioral change among alcoholics, we took into account these personality, emotional, mental health, demographic, and narrative variables. Our theoretical account presupposes that the narration of 
self-redemption is, in and of itself, predictive of behavioral change, but it is also possible that this narrative theme is associated with change because of shared associations with certain adaptive traits (e.g., optimism) or other beneficial elements of the narrative itself (e.g., the proportion of positive emotion words). Thus, these variables were treated as covariates in relevant analyses.

\section{Study 1}

In Study 1, we compared the prevalence of themes of selfredemption in the narratives produced by alcoholics who had maintained their sobriety for 4 years or longer with that of narratives produced by alcoholics who had maintained their sobriety for 6 months or less. We predicted that alcoholics who had maintained their sobriety for a substantial period would be more likely to produce a story about their last drink that contained selfredemption than alcoholics who were newly sober. In addition, because variables such as optimism, depression, trait positive and negative affect, anxiety, attribution style, alcohol dependence, recovery program involvement, and general health have been shown to correspond with recovery from alcohol addiction (e.g., Dawson et al., 2005; Moos \& Moos, 2006; Willinger et al., 2002), we assessed these variables and tested whether any relation between self-redemption and sobriety length might be attributed to them. We also tested whether observed relations could be attributed to the microanalytic content of narratives found in previous research to correspond to certain health behaviors and well-being (viz. positive emotion words, negative emotion words, insight words, and causal words; see Pennebaker \& Chung, 2011).

\section{Method}

Participants and procedure. Thirty-seven self-identified recovering alcoholics who reported maintaining their sobriety for at least 4 years ("long-term sober" group; see Table 1 for descriptive information about this subsample) and 95 self-identified recovering alcoholics who reported maintaining their sobriety for 6 months or less ("short-term sober" group; see Table 2) were recruited from AA meetings located in and around Vancouver, British Columbia, Canada, and were paid $\$ 40$ for their participation. ${ }^{1}$ After providing informed consent, participants were taken to a private room and instructed to

Please think about the last time you drank alcohol and felt bad about yourself as a result. This might be a time when you slipped from your sobriety. Please describe in as much detail as possible what happened, how it made you feel, and what you did in response to this event.

Although we did not ask participants to indicate when this event transpired, we did ask them to report the length of time they had been sober, which we assumed would correspond with the length of time since their narrated event occurred.

In contrast to some previous research examining redemptive themes in narratives (e.g., Adler \& Poulin, 2009), we did not directly ask participants whether they had made sense of the event in question, or perceived a positive benefit emerging from it, to avoid priming participants to produce redemptive responses. ${ }^{2}$ In this way, we were able to capture individual differences in the tendency to spontaneously redeem this significant event in the life of an addict. Responses were video-recorded and later transcribed verbatim. ${ }^{3}$ Following this task, participants completed a battery of questionnaires and reported the number of months they had been AA members.

Narrative measures. Transcribed narratives about participants' last drink were coded for self-redemption by a research assistant blind to all hypotheses as well as participants' demographic information (including sobriety length). This coding system drew heavily upon the work of McAdams (e.g., McAdams, 2006; McAdams et al., 2001), but was modified to focus on self-redemption (i.e., identifying a positive change in the self following a negative experience), rather than redemption writ large. Doing so required incorporating the theorizing of Pasupathi, Mansour, and Brubaker (2007), who equated redemption with the description of positive self-change following a negative and/or formative experience (see also Pasupathi \& Mansour, 2006). For self-redemption to be identified in a given narrative, participants must have described their last drinking experience as causing a personal change conducive to sobriety (e.g., "becoming stronger"; see Table 2 for examples of redemptive and nonredemptive narratives). To determine the reliability of this coding system, a secondary coder rated a quarter of the narratives (91\% agreement, $k=.78)$.

In addition to coding for redemption, we analyzed participants' narratives using the Linguistic Inquiry and Word Count computer program (LIWC; Pennebaker, Booth, \& Francis, 2007). The LIWC assesses the microanalytic content of narrative passages, identifying the prevalence of certain words and phrases (e.g., personal pronouns, negative emotion words). We considered four metrics that have been found in previous research to predict health behaviors and psychological adjustment: the percentage of (a) positive emotion words, (b) negative emotion words, (c) insight words, and (d) causal words (see Pennebaker \& Chung, 2011).

\section{Self-report measures.}

Optimism. Optimism was assessed with the eight-item Life Orientation Test-Revised (Scheier, Carver, \& Bridges, 1994; $\alpha=$ .82). Exemplary items include "In uncertain times, I usually expect the best" and "I'm always optimistic about the future." Participants rated each item on a 5-point scale ranging from strongly disagree to strongly agree.

Depression. Depression was assessed with the seven-item depressed affect scale of the Center for Epidemiologic Studies Depression Scale (CES-D; Radloff, 1977; $\alpha=.89$ ). This measure quantifies the degree to which respondents experience negative affect relevant to depression (e.g., sadness, loneliness). Participants rated each item on a 4-point scale ranging from less than one day to five to seven days to indicate their feelings or behaviors during the previous week. Exemplary items include "I felt lonely" and "I had crying spells."

\footnotetext{
${ }^{1}$ The present study is part of a larger project examining recovery from alcoholism. In addition to the participants included in Studies 1 and 2, 14 other AA members completed measures but were not included in the current sample because they did not report the number of months they had maintained sobriety prior to their participation.

${ }^{2}$ Supporting this expectation, only $35 \%$ of participants in Study 1 and $27 \%$ in Study 2 produced a narrative containing self-redemption.

${ }^{3}$ Seven participants elected to write, rather than orally produce, their stories. Written narratives were similarly transcribed verbatim.
} 
Table 1

Descriptive Statistics for Long-Term and Short-Term Sober Participants (Study 1)

\begin{tabular}{|c|c|c|c|c|c|}
\hline \multirow[b]{2}{*}{ Variable } & \multicolumn{2}{|c|}{ Long-term sober $(n=37)$} & \multicolumn{2}{|c|}{ Short-term sober $(n=95)$} & \multirow{2}{*}{$\begin{array}{c}\text { Group } \\
\text { comparison }(p)\end{array}$} \\
\hline & $M$ & $S D$ & $M$ & $S D$ & \\
\hline \multicolumn{6}{|l|}{ Demographic measures } \\
\hline Age (years) & 53.59 & 13.04 & 38.36 & 9.94 & $<.001$ \\
\hline Gender (\% women) & 54.10 & & 56.80 & & 1 \\
\hline Ethnicity (\% Caucasian) & 75.70 & & 74.70 & & 1 \\
\hline Length of sobriety (months) & 185.90 & 107.11 & 2.57 & 1.50 & $<.001$ \\
\hline \multicolumn{6}{|l|}{ Self-report measures } \\
\hline Optimism & 2.93 & 0.77 & 2.32 & 0.80 & $<.001$ \\
\hline Depression & 0.74 & 0.70 & 1.34 & 0.79 & $<.001$ \\
\hline Trait positive affect & 3.82 & 0.50 & 3.51 & 0.67 & .01 \\
\hline Trait negative affect & 2.14 & 0.84 & 2.78 & 0.86 & $<.001$ \\
\hline Anxiety & 0.62 & 0.76 & 1.49 & 1.00 & $<.001$ \\
\hline Controllability attributions & 7.02 & 0.66 & 7.06 & 0.92 & .81 \\
\hline Alcohol dependence & 1.99 & 0.42 & 1.98 & 0.31 & .86 \\
\hline AA involvement & 1.82 & 0.27 & 1.68 & 0.20 & .001 \\
\hline Months in AA & 189.88 & 113.44 & 56.41 & 68.72 & $<.001$ \\
\hline General health & 67.22 & 20.22 & 57.23 & 23.56 & .03 \\
\hline \multicolumn{6}{|l|}{ Narrative measures } \\
\hline Length (words) & 385.92 & 432.95 & 225.42 & 194.65 & .004 \\
\hline Positive emotion words & 1.98 & 1.46 & 2.08 & 1.21 & .68 \\
\hline Negative emotion words & 1.77 & 1.39 & 2.81 & 2.29 & .01 \\
\hline Insight words & 3.24 & 1.81 & 3.29 & 1.78 & .86 \\
\hline Causal words & 1.75 & 1.46 & 1.56 & 1.15 & .45 \\
\hline Redemption (\%) & 54.10 & & 27.40 & & .01 \\
\hline
\end{tabular}

Note. Long-term sober participants reported a length of sobriety equal to or greater than 4 years. Short-term sober participants reported a length of sobriety equal to or less than 6 months. $\mathrm{AA}=$ Alcoholics Anonymous.

Trait positive and negative affect. Trait positive and negative affect were assessed with the 20-item Positive and Negative Affect Schedule (Watson, Clark, \& Tellegen, 1988; $\alpha$ s $=.85$ and .92, respectively). Participants were asked to rate, on a 5-point scale ranging from not at all to extremely, the degree to which they generally experience each of a set of specific emotions. Scores of positive affect were derived by averaging the ratings of the 10 items corresponding to active, alert, and enthusiastic affective states, and scores of negative affect were derived by averaging the rating of the 10 items corresponding to unpleasant emotions.
Anxiety. Participants completed the anxiety subscale of Derogatis's (1975) Brief Symptom Inventory $(\alpha=.87)$. This measure prompts participants to rate (on a 5-point scale, with larger numbers corresponding with greater values) the level of distress experienced over the preceding week as a result of certain sensations or events.

Controllability attributions. Controllability attributions were assessed with the 24-item ability and effort scales of the Multidimensional-Multiattributional Causality Scale (MMCS; Lefcourt, Von Baeyer, Ware, \& Conx, 1979; $\alpha=.72)$. The MMCS

Table 2

Examples of Redemptive and Nonredemptive Narratives

\begin{tabular}{|c|c|}
\hline Redemptive narrative & Nonredemptive narrative \\
\hline $\begin{array}{l}\text { I got uh, quite wasted, I was seven months clean, and then that month I uh, } \\
\text { I relapsed quite a few times, and uh, as a result, I uh, slit my wrist, } \\
\text { ended up in the psych ward at Vancouver General Hospital, and uh, I } \\
\text { had to take a step back in my life, I was involved with a guy from } \\
\text { federal prison, he was in the program of recovery, NA and AA, and uh, } \\
\text { he relapsed, and I jumped in to follow. And uh, it started off with } \\
\text { alcohol, and every time I drank, I would end up going to crack, or to } \\
\text { needle injection cocaine and heroin, and that's where I ended up, that's } \\
\text { when I slit my wrist, so it was a pretty horrible experiences, I was } \\
\text { feeling useless, unloved, lonely, depressed, ashamed, that I, you know, } \\
\text { fell through on my recovery plan, and after losing seven months you } \\
\text { almost lose hope, right? But uh, I found my own strength again, through } \\
\text { God, and through the NA and AA program, } 11 \text { days clean, I feel like the } \\
\text { obsession has been lifted from me again, and I need to see everything I }\end{array}$ & $\begin{array}{l}\text { I had um many uh about ten beer at a friend's backyard barbeque } \\
\text { during the afternoon and evening and um I wasn't in the } \\
\text { program of AA at the time, and um, just didn't like um, that } \\
\text { evening after I had moved onto another house, I found myself } \\
\text { just uh beating myself up internally about things I'd said at } \\
\text { this barbeque being a little, uh, loose with my words, } \\
\text { inappropriate and um seemed all joking at the time but uh, um } \\
\text { might have caused a bit of damaged so felt bad about that and } \\
\text { after I left the party, I um, I picked up a harder substance } \\
\text { [sigh] and um didn't pick up any alcohol after that for a couple } \\
\text { of days. And um, but uh yeah, I definitely remember feeling } \\
\text { bad about how my choice of language and subject matter in } \\
\text { the conversation that had while I was drinking was } \\
\text { inappropriate. That's it. }\end{array}$ \\
\hline
\end{tabular}

Note. Italicized text represents the portion of the narrative indicating redemption. NA = Narcotics Anonymous; AA = Alcoholics Anonymous. 
assesses the degree to which participants believe that their successes and failures are a product of ability and effort in both achievement (i.e., school) and affiliative (i.e., interpersonal) domains. Attributional styles tend to be consistent across domains, including those not directly assessed by the MMCS (see Peterson, 1991). Controllability attributions were targeted because these have been found to correspond with alcohol addiction and recovery (e.g., Dowd et al., 1986). Participants rated each item on a 5-point scale ranging from disagree to agree. Exemplary items from the ability scale include "If I were to receive low marks it would cause me to question my academic ability" and "It seems to me that getting along with people is a skill." Exemplary items from the effort scale include "When I fail to do as well as expected in school, it is often due to a lack of effort" and "Maintaining friendships requires real effort to make them work."

Alcohol dependence. We assessed participants' level of alcohol dependence using the 25-item Alcohol Dependence Scale (Skinner \& Allen, 1992; $\alpha=.88$ ). This questionnaire measures both the degree to which respondents experience negative physical symptoms as a result of drinking and their inability to drink in moderation (of note, high scores on this scale indicate the extent of dependence regardless of participants' current level of alcohol consumption; thus, a participant might at present be sober yet still receive a high score). It consists of a series of items rated on a continuous scale or responded to in the affirmative or negative. Higher responses on items relying upon a continuous scale are indicative of greater alcohol dependence, as are questions answered in the affirmative.

AA involvement. We assessed the degree to which participants were involved with AA using the eight dichotomous (i.e., yes/no) items from the Alcoholics Anonymous Involvement Scale (Tonigan, Connors, \& Miller, 1996; $\alpha=.71$ ). Exemplary items from this measure include "Have you ever had an AA sponsor" and "Have you ever celebrated an AA sobriety birthday?" Affirmative responses were coded 2 , whereas negative responses were coded 1 (i.e., higher values indicated greater AA involvement). Values were averaged to arrive at a single score.

General health. General health was assessed with the fiveitem general health scale of the RAND Health Survey (Ware \& Sherbourne, 1992; $\alpha=.76$ ). This measure taps the degree to which participants believe that their physical and mental health is, and will remain, excellent. Participants rated items on a 5-point scale with larger numbers indicating a more favorable evaluation of personal health. General health scores were derived by averaging these five items.

\section{Results and Discussion}

Supporting our predictions, long-term sober alcoholics (i.e., those who had been sober 4 years or more) were significantly more likely than short-term sober alcoholics (i.e., those sober 6 months or less) to include the profession of self-redemption in the narration of their last drinking experience, $\chi^{2}(1)=7.22, p=.007$. The relation between redemption and sobriety remained significant after controlling for optimism, depression, trait positive and negative affect, anxiety, controllability attributions, alcohol dependence, AA involvement, months in AA, general health, the length of participants' narratives, and the number of positive emotion words, negative emotion words, insight words, and causal words in these narratives, $F(1,110)=4.03, p=.047, \eta_{\mathrm{p}}^{2}=.04$ (see Table 3 for intercorrelations among all continuous self-report and narrative measures). ${ }^{4}$

As is apparent from Table 1, the long-term sober group was substantially older than the short-term sober group. Thus, we next examined whether the two groups differed in the prevalence of self-redemption after controlling for age, a demographic variable likely to influence both recovery and a tendency to view negative events as stimulating personal development (Pasupathi \& Mansour, 2006). After accounting for this covariate, the long-term sober group was still found to exhibit a significantly higher level of self-redemption than the short-term sober group, $F(1,129)=$ $4.52, p=.035, \eta_{\mathrm{p}}^{2}=.03$, signifying that this difference cannot be attributed to the variability in age between groups.

Collectively, these results suggest that the longer recovering alcoholics have sustained their sobriety, the more likely they are to perceive their most recent drinking experience as stimulating a positive change in their personality. The current findings are thus consistent with the notion that the narration of self-redemption is predictive of extended behavioral change. However, given Study 1 's cross-sectional design, we cannot determine whether, as predicted, the perception of self-redemption precedes extended sobriety, or whether the tendency to narrate one's last drink as stimulating a positive change in the self represents a post hoc construction following extended abstinence. Study 2 was conducted to address this ambiguity.

\section{Study 2}

To test whether the construction of a narrative containing selfredemption precedes behavioral change, we tracked the short-term sober sample from Study 1 over time, after they had produced their narratives, to examine subsequent changes in behavior and health. We predicted that those participants who had professed selfredemption at Wave 1 would be more likely to have maintained sobriety at Wave 2 relative to nonredemptive participants. Due to the correspondence between redemption and psychological adjustment (e.g., McAdams et al., 2001), we also predicted that our redemptive group would exhibit greater gains in general health relative to the nonredemptive group.

\section{Participants and Procedure}

Of the participants initially recruited for the short-term sober sample, $46 \%(n=44)$ returned several months later for a follow-up assessment, and received an additional $\$ 40$ for doing so. Although this indicates a high attrition rate, it is not surprising given that many participants lived in halfway houses or other unstable situations and, for these reasons, were difficult to locate. To test for selective retention, we examined whether any of the demographic, personality, emotion, alcohol dependence, program involvement, or narrative variables assessed at Wave 1 distin-

\footnotetext{
${ }^{4}$ Results were largely comparable when sobriety was treated as a continuous variable (i.e., months of sobriety) rather than an indicator of group membership. Specifically, a positive relation emerged between months of sobriety and the profession of redemption $\left(r_{\mathrm{pb}}=.22, p=.02\right)$. This relation held after controlling for all covariates specified in the main text $\left(r_{\mathrm{pb}}=.20, p=.04\right)$.
} 
Table 3

Intercorrelations Among Continuous Variables (Study 1)

\begin{tabular}{|c|c|c|c|c|c|c|c|c|c|c|c|c|c|c|c|c|}
\hline Variable & 1 & 2 & 3 & 4 & 5 & 6 & 7 & 8 & 9 & 10 & 11 & 12 & 13 & 14 & 15 & 16 \\
\hline \multicolumn{17}{|c|}{ Self-report measures } \\
\hline 1. Optimism & - & & & & & & & & & & & & & & & \\
\hline 2. Depression & $-.56^{* *}$ & - & & & & & & & & & & & & & & \\
\hline $\begin{array}{l}\text { 3. Trait positive } \\
\text { affect }\end{array}$ & $50^{* * *}$ & $-32^{* *}$ & - & & & & & & & & & & & & & \\
\hline 4. Trait negative & & & & & & & & & & & & & & & & \\
\hline affect & $-.58^{* * *}$ & $.65^{* *}$ & -.26 & - & & & & & & & & & & & & \\
\hline 5. Anxiety & $-.53^{* * *}$ & $.75^{* * *}$ & -.26 & $.70^{* * *}$ & - & & & & & & & & & & & \\
\hline $\begin{array}{l}\text { 6. Controllability } \\
\text { attributions }\end{array}$ & -.02 & .08 & .11 & .16 & .14 & - & & & & & & & & & & \\
\hline 7. Alcohol & & & & & & & & & & & & & & & & \\
\hline dependence & -.14 & .19 & .04 & .20 & .22 & .15 & - & & & & & & & & & \\
\hline 8. AA involvement & .10 & -.24 & .14 & -.08 & -.13 & .12 & .14 & - & & & & & & & & \\
\hline 9. Months in AA & .33 & -.28 & .10 & -.28 & -.28 & .00 & .07 & .44 & 一 & & & & & & & \\
\hline 10. General health & $.54^{* *}$ & $-.42^{* * *}$ & $.36^{* * *}$ & $-.43^{* *}$ & $-.48^{* *}$ & -.12 & -.15 & .15 & .19 & - & & & & & & \\
\hline \multicolumn{17}{|c|}{ Narrative measures } \\
\hline 11. Length (in words) & .03 & -.12 & .04 & -.05 & -.02 & .14 & .04 & .11 & .08 & -.05 & - & & & & & \\
\hline 12. Positive emotion & & & & & & & & & & & & & & & & \\
\hline words & -.11 & .14 & -.04 & .08 & .14 & .12 & -.17 & -.01 & -.10 & .00 & .00 & - & & & & \\
\hline $\begin{array}{l}\text { 13. Negative emotion } \\
\text { words }\end{array}$ & -.24 & .11 & -.08 & .13 & .05 & .05 & .04 & .03 & -.18 & .24 & -.27 & .05 & - & & & \\
\hline 14. Insight words & -.04 & .15 & -.04 & .12 & $.33^{* *}$ & -.13 & $\begin{array}{r}.04 \\
-.10\end{array}$ & .10 & $\begin{array}{l}.10 \\
-.07\end{array}$ & $\begin{array}{r}.24 \\
-.06\end{array}$ & .10 & .08 & $\overline{.01}$ & - & & \\
\hline 15. Causal words & .07 & .01 & .08 & .03 & -.02 & .16 & -.07 & .07 & -.06 & -.05 & -.05 & .04 & .05 & .22 & - & \\
\hline 16. Redemption & .04 & -.04 & .13 & -.07 & -.12 & .04 & .06 & .06 & .08 & .08 & .08 & -.10 & -.18 & -.06 & .02 & - \\
\hline
\end{tabular}

Note. $\mathrm{AA}=$ Alcoholics Anonymous.

*** $p<.0004$ (level of significance following a Bonferroni correction).

guished participants who did and did not return for Wave 2. As is apparent from Table 4 (which provides a summary of the profiles of participants who did and did not return for the follow-up assessment), those who returned for the Wave 2 assessment exhibited a higher level of optimism, lower levels of anxiety and negative affect, and fewer causal words in their narratives, compared to those who did not return, but the two groups did not differ in the majority of variables considered, including our key predictor variable-self-redemption. Nonetheless, to ensure that results found in Study 2 could not be attributed to the few significant differences between those who did and did not complete our follow-up, we included all the covariates from Study 1 (including optimism, anxiety, negative affect, and causal words) in our analyses. Wave 2 assessments were conducted an average of 4 months after Wave $1(S D=1.79$; range: $2-11)$. This time frame was targeted in the interest of capturing a period when relapse would be particularly high; previous research has suggested that most relapses occur within the first 3 months of sobriety (Hunt, Barnett, \& Branch, 1971; Kirshenbaum, Olsen, \& Bickel, 2009). At Wave 2 participants completed the same measure of general health as was used at Wave $1(\alpha=.79)$, allowing us to assess changes in health between the two waves. Participants were also asked to report the number of months they had maintained their sobriety. For each participant, this number was compared to the number of months between assessments to determine whether relapse had occurred since the production of the Wave 1 narratives. To reduce biased responding, participants were not directly asked whether they had relapsed between assessments (Bowling, 2005).

\section{Results and Discussion}

Participants were categorized into groups on the basis of whether their Wave 1 narratives did $(n=12)$ or did not $(n=32)$ contain self-redemption (see Table 5 for a summary of differences between these groups on Wave 1 measures). Although $43 \%$ of participants, overall, relapsed between waves, consistent with our hypothesis and the results of Study 1, Wave 1 self-redemption significantly predicted the maintenance of sobriety across waves; $83 \%$ of participants whose narrative contained a description of positive self-change maintained sobriety between assessments, compared to $44 \%$ of nonredemptive participants, $\chi^{2}(1)=5.11$, $p=.024$. Furthermore, the effect of self-redemption on sobriety remained significant after controlling for length of time between assessments, relevant personality traits (i.e., optimism, depression, trait affect, anxiety, controllability attributions), recovery program commitment (i.e., AA involvement, months in AA), general health, narrative length, and the prevalence of positive emotion words, negative emotion words, insight words, and causal words within participants' stories, $F(1,20)=8.75$, $p=.008, \eta_{\mathrm{p}}^{2}=.30$ (see Table 6).

Redemptive participants also demonstrated greater improvement in general health at Wave 2 (i.e., higher Wave 2 scores controlling for Wave 1 scores) compared to nonredemptive participants, $F(1,40)=5.56, p=.023, \eta_{\mathrm{p}}^{2}=.12$. This effect remained significant after controlling for length of time between assessments, relevant personality traits, AA involvement, months in AA, physical and mental health, and the length and 
Table 4

Descriptive Statistics for Short-Term Sober Participants Who Did and Did Not Return for the Wave 2 Assessment (Study 2)

\begin{tabular}{|c|c|c|c|c|c|}
\hline \multirow[b]{2}{*}{ Variable } & \multicolumn{2}{|c|}{$\begin{array}{l}\text { Returned for Wave } 2 \\
\quad(n=44)\end{array}$} & \multicolumn{2}{|c|}{$\begin{array}{l}\text { Did not return for Wave } 2 \\
\qquad(n=51)\end{array}$} & \multirow{2}{*}{$\begin{array}{c}\text { Group } \\
\text { comparison } \\
(p)\end{array}$} \\
\hline & $M$ & $S D$ & $M$ & $S D$ & \\
\hline \multicolumn{6}{|l|}{ Demographic measures } \\
\hline Age (years) & 40.17 & 10.23 & 36.53 & 9.41 & .08 \\
\hline Gender (\% women) & 56.80 & & 55.10 & & .76 \\
\hline Ethnicity (\% Caucasian) & 70.50 & & 79.60 & & .16 \\
\hline Length of sobriety (months) & 2.68 & 1.51 & 2.44 & 1.52 & .44 \\
\hline \multicolumn{6}{|l|}{ Self-report measures } \\
\hline Optimism & 2.56 & 0.81 & 2.09 & 0.73 & .004 \\
\hline Depression & 1.19 & 0.74 & 1.46 & 0.82 & .11 \\
\hline Trait positive affect & 3.49 & 0.72 & 3.53 & 0.62 & .80 \\
\hline Trait negative affect & 2.58 & 0.84 & 2.96 & 0.86 & .04 \\
\hline Anxiety & 1.19 & 0.90 & 1.76 & 1.03 & .01 \\
\hline Controllability attributions & 6.92 & 1.05 & 7.18 & 0.80 & .19 \\
\hline Alcohol dependence & 1.93 & 0.35 & 2.02 & 0.27 & .16 \\
\hline AA involvement & 1.66 & 0.19 & 1.71 & 0.19 & .19 \\
\hline Months in AA & 50.89 & 62.73 & 61.99 & 74.98 & .46 \\
\hline General health & 59.91 & 24.62 & 55.99 & 21.66 & .42 \\
\hline \multicolumn{6}{|l|}{ Narrative measures } \\
\hline Length (words) & 239.93 & 195.50 & 215.49 & 198.55 & .55 \\
\hline Positive emotion words & 1.99 & 1.16 & 2.16 & 1.27 & .49 \\
\hline Negative emotion words & 2.57 & 1.88 & 3.04 & 2.60 & .32 \\
\hline Insight words & 2.95 & 1.80 & 3.62 & 1.73 & .07 \\
\hline Causal words & 1.28 & 1.10 & 1.84 & 1.14 & .02 \\
\hline Redemption (\%) & 27.27 & & 28.57 & & .89 \\
\hline
\end{tabular}

Note. $\mathrm{AA}=$ Alcoholics Anonymous.

microanalytic content of the narratives themselves, $F(1,21)=$ $4.38, p=.049, \eta_{p}^{2}=.17$.

In summary, participants who produced a narrative containing self-redemption were more likely to maintain sobriety following their initial participation relative to participants whose narratives did not evince such themes. In addition, redemptive individuals exhibited a greater increase in general health between assessments than nonredemptive participants. The current findings are particularly noteworthy given that redemptive and nonredemptive participants were essentially indistinguishable at Wave 1, in terms of demographics, personality, health, alcohol dependence, and recovery program involvement, yet were clearly already on route to highly divergent recovery trajectories. These results are thus consistent with the notion that, at least within the domain of alcohol addiction, the formation of a personal narrative in which a negative experience is construed as causing a positive change in the self precedes - and may be a causal factor underlying-long-term behavioral change.

\section{General Discussion}

Psychological scientists have long recognized the life story as the story we live by (McAdams, 1985, 1993), with several theorists proposing that, once formed, this narrative exhibits a causal influence on subsequent behavior (e.g., Giddens, 1991; Wilson, 2002). Furthermore, many behavioral reform programs place an emphasis on the construction of a certain type of story, one in which the self is improved as a result of the difficult experiences it has faced, in the interest of stimulating long-term behavioral change (Diamond, 2001; O'Reilly, 1997). Despite the assumptions inherent in these theoretical perspectives and practices, few researchers have exam- ined whether life narratives in fact predict substantive behavioral change. The present research is the first to demonstrate that (a) there is a strong association between the tendency to perceive past traumatic life events as resulting in positive personality change and corresponding behavioral change, and (b) the perception of positive personality change predicts subsequent positive behavioral change. These findings are based on a sample of individuals who were studied while in the process of recovering from a major traumatic life event (i.e., alcoholics, both actively struggling with sobriety and relatively adjusted to a sober lifestyle), underscoring their ecological validity. Furthermore, these results held across two distinct analyses (i.e., cross-sectional and longitudinal), highlighting the robustness of our findings.

In our cross-sectional analysis, alcoholics who had maintained sobriety for 4 years or longer were significantly more likely to describe their most recent drinking experience (prior to sobriety) as stimulating a positive development in the self, compared to alcoholics who had maintained sobriety for 6 months or less. Though this pattern may have been due to post hoc construals on the part of the long-term sober group, our longitudinal findings make this possibility unlikely. Indeed, in our longitudinal analysis, newly sober alcoholics who perceived a sense of self-redemption in the wake of their recent sobriety demonstrated improved health months later, and were over twice as likely to have maintained sobriety across the two waves of assessment than those who did not evince any sense of self-redemption in their stories during the initial wave. Newly sober alcoholics who did and did not profess self-redemption were indistinguishable at Wave 1 in terms of age, gender, education, ethnicity, mental and physical health, personality, involvement in AA, and the length and microanalytic content 
Table 5

Descriptive Statistics for Newly Sober Participants Included in Study 2 Who Produced a Redemptive Sequence in Their Narrative and Those Who Did Not at Initial Assessment

\begin{tabular}{|c|c|c|c|c|c|}
\hline \multirow[b]{2}{*}{ Variable } & \multicolumn{2}{|c|}{$\begin{array}{l}\text { Redemptive subsample } \\
\qquad(n=12)\end{array}$} & \multicolumn{2}{|c|}{$\begin{array}{l}\text { Nonredemptive subsample } \\
\qquad(n=32)\end{array}$} & \multirow{2}{*}{$\begin{array}{c}\text { Group } \\
\text { comparison } \\
(p)\end{array}$} \\
\hline & $M$ & $S D$ & $M$ & $S D$ & \\
\hline \multicolumn{6}{|l|}{ Demographic measures } \\
\hline Age (years) & 41.13 & 9.39 & 39.81 & 10.65 & .71 \\
\hline Gender ( $\%$ women) & 66.70 & & 53.10 & & .48 \\
\hline Ethnicity (\% Caucasian) & 3.17 & 1.51 & 2.51 & 1.49 & .20 \\
\hline Length of sobriety (months) & 3.42 & 2.01 & 2.86 & 2.03 & .42 \\
\hline Time between assessments (months) & 3.75 & 1.42 & 4.06 & 1.92 & .61 \\
\hline \multicolumn{6}{|l|}{ Self-report measures } \\
\hline Optimism & 2.61 & 0.82 & 2.54 & 0.83 & .80 \\
\hline Depression & 1.05 & 0.65 & 1.27 & 0.67 & .34 \\
\hline Trait positive affect & 3.65 & 0.80 & 3.43 & 0.69 & .38 \\
\hline Trait negative affect & 2.37 & 0.89 & 2.66 & 0.82 & .30 \\
\hline Anxiety & 0.92 & 0.78 & 1.33 & 0.92 & .18 \\
\hline Controllability attributions & 3.71 & 1.00 & 3.93 & 1.40 & .63 \\
\hline Alcohol dependence & 1.95 & 0.34 & 1.92 & 0.37 & .85 \\
\hline AA involvement & 1.67 & 0.16 & 1.63 & 0.24 & .51 \\
\hline Months in AA & 21.00 & 37.19 & 61.85 & 66.99 & .06 \\
\hline General health & 68.33 & 21.46 & 56.65 & 25.30 & .17 \\
\hline \multicolumn{6}{|l|}{ Narrative measures } \\
\hline Length (words) & 272.25 & 224.89 & 227.81 & 185.78 & .51 \\
\hline Positive emotion words & 1.87 & 1.50 & 2.03 & 1.02 & .71 \\
\hline Negative emotion words & 2.17 & 1.18 & 2.72 & 2.08 & .40 \\
\hline Insight words & 3.24 & 1.52 & 2.84 & 1.91 & .51 \\
\hline Causal words & 1.29 & 0.82 & 1.28 & 1.19 & .97 \\
\hline
\end{tabular}

Note. $\quad \mathrm{AA}=$ Alcoholics Anonymous.

of their stories; and the effect of self-redemption on recovery remained significant after controlling for all of these variables. These results are suggestive of the possibility that developing a story of self-redemption about one's addiction may be a causal factor underlying long-term behavioral change.

The current findings thus lay the groundwork, and provide a compelling rationale, for future experimental intervention studies testing this causal account. Individuals who have experienced many different kinds of difficult life events can, presumably, come to conceptualize these events as contributing to the positive development of the self, and eventually develop a narrative that emphasizes positive personality change (Wilson, 2002). If developing a personal narrative containing self-redemption is, in fact, causally predictive of the effects reported here, practitioners could target this form of narrative as a potential means of treatment.

There are, however, several cautions that should be heeded by researchers examining the relation between self-redemption and behavioral change by way of experimental design. First, it is likely the case that certain individuals will find it easier to construct a narrative containing self-redemption than others. Indeed, in previous work (Dunlop \& Tracy, 2012) we proposed that given the canonical status of redemptive narratives writ large and especially within self-help programs, some may seek to construct a narrative of self-redemption out of an inclination to conform to societal pressures, yet experience a conflict between these pressures and the desire to maintain a sense of personal authenticity. Furthermore, in his research on chronically addicted men, Singer (1997) cited an incompatibility between the lives these men had led and the stories endorsed by recovery programs such as AA. The life story is, after all, a psychosocial construction (McAdams et al., 2001), formed partly on the basis of actual events and partly on one's interpretation of those events.

Just as certain individuals may be more redemptive in a dispositional sense, so too may certain events be more likely to be redeemed relative to others. In the current research, we relied upon a standard event (i.e., the last drink) and found that the relation between self-redemption in the narration of this event and sobriety remained significant after taking into account a host of demographic, personality, and narrative variables. Nonetheless, it remains possible that those participants who constructed a narrative containing self-redemption, or those drinking experiences that were ultimately redeemed, were somehow qualitatively different from those individuals and drinking experiences that were not.

Second, there is limited prior evidence to suggest that, for some, constructing a coherent narrative is associated with reduced psychological adjustment. Examining the relation between the sophistication of adolescent males' narratives in relation to well-being, McLean, Breen, and Fournier (2010) observed that, among younger (but not older) adolescence males, the creation of a complex narrative was associated with lower (rather than higher) levels of well-being. Interpreting this finding, McLean and Mansfield (2011) suggested that the relation between narrative content and well-being may be mediated by certain personal and cultural factors. Given the emphasis on redemption within Western culture (McAdams, 2006), it remains an open question as to whether the relations identified in the current research preside in differing cultural contexts. 
Table 6

Predicting Sobriety and Change in Health From Redemption, Controlling for Time Between Assessments, Initial Levels of Relevant Personality Traits, Alcohol Dependence, Recovery Program Involvement, Health, and Microanalytic Narrative Content at Wave 2 (Study 2)

\begin{tabular}{|c|c|c|c|c|}
\hline \multirow[b]{2}{*}{ Variable } & \multicolumn{2}{|c|}{ Sobriety } & \multicolumn{2}{|c|}{ General health } \\
\hline & $\beta$ & $t(20)$ & $\beta$ & $t(21)$ \\
\hline Time between assessments (months) & $-.27^{*}$ & 2.07 & -.11 & 0.61 \\
\hline \multicolumn{5}{|l|}{ Self-report measures } \\
\hline Optimism & $.37^{\dagger}$ & 1.72 & .15 & 0.53 \\
\hline Depression & -.27 & 1.50 & .15 & 0.63 \\
\hline Trait positive affect & -.13 & 0.83 & .09 & 0.43 \\
\hline Trait negative affect & $.40^{*}$ & 2.47 & .05 & 0.24 \\
\hline Anxiety & -.01 & 0.01 & .06 & 0.31 \\
\hline Controllability attributions & .16 & 1.40 & .11 & 0.69 \\
\hline Alcohol dependence & .13 & 0.89 & -.11 & 0.64 \\
\hline AA involvement & $.29^{*}$ & 2.00 & .05 & 0.29 \\
\hline Months in AA & $-.42^{*}$ & 3.20 & $-.38^{*}$ & 2.22 \\
\hline General health (Wave 1) & $.49^{*}$ & 3.39 & $.64^{*}$ & 3.32 \\
\hline \multicolumn{5}{|l|}{ Narrative measures } \\
\hline Length (in words) & -.13 & 0.80 & -.03 & 0.12 \\
\hline Positive emotion words & -.02 & 0.14 & .14 & 0.88 \\
\hline Negative emotion words & .22 & 1.52 & .18 & 0.93 \\
\hline Insight words & -.08 & 0.52 & .09 & 0.45 \\
\hline Causal words & -.09 & 0.69 & .02 & 0.14 \\
\hline Predictor: Redemption & $.29^{*}$ & 2.96 & $.29^{*}$ & 2.09 \\
\hline
\end{tabular}

Note. $\mathrm{AA}=$ Alcoholics Anonymous.

${ }^{\dagger} p<.10 .{ }^{*} p<.05$.

The current results suggest that that the construction of a narrative containing self-redemption precedes long-term behavioral change. However, this finding does not preclude the possibility that, in certain cases, stories of self-redemption are formed in a post hoc manner following behavioral change. Bem (1972) proposed that we derive an understanding of ourselves largely as a result of observing our behaviors, rather than behaving in a manner consistent with some previously established sense of selfunderstanding. With this perspective applied to the present results, the long-term sober alcoholics included in Study 1 might have constructed their stories of personal improvement following, rather than prior to, their extended sobriety. Although this perspective fails to account for the results of Study 2, in which self-redemption predicted subsequent sobriety and improvements in health among a sample of newly sober alcoholics, it does suggest that those newly sober participants in Study 2 who maintained sobriety between assessments but did not produce a redemptive narrative at Wave 1 may ultimately come to form a personal story which includes the profession of self-redemption. To test this possibility, future longitudinal studies are needed to assess the same narrative repeatedly over time.

Irrespective of whether, in select cases, the construction of a narrative containing self-redemption represents a post hoc undertaking following behavioral change, the current results suggest that the assessment of themes of self-growth in recovery narratives can provide an efficient and effective means of determining future risk for those beginning the recovery process. For this reason, the present findings may have important implications for the understanding and treatment of problematic behavioral patterns in a variety of domains. Assessing themes of self-redemption in the stories told by those coping with addiction as well as other intran- sient behavioral problems (e.g., criminality, overeating) may allow for improved prediction of individual recovery trajectories.

Despite the contributions made by the current research, this project had several limitations that should be addressed in subsequent research. The first corresponds to our method of assessing sobriety and relapse. Although we took measures to assess relapse in a manner that likely decreased the influence of self-presentation biases (i.e., we did not explicitly ask participants if they relapsed since Wave 1; instead we simply asked them to report the date of their last drink, without reminding them the date of their Wave 1 assessment; Bowling, 2005), we did rely upon self-reports of drinking behaviors, so future studies are needed to replicate the present findings using a more objective means of assessing drinking behavior (e.g., corroborator reports, medical records). However, it is worth noting that although certain recovery programs may incentivize participants to mask a relapse (Diamond, 2001), on the whole, self-report measures of alcohol consumption have been found to be reliable and valid (Del Boca \& Darkes, 2003; Hesselbrock, Babor, Hesselbrock, Meyer, \& Workman, 1983). Furthermore, within AA, incentives to mask relapses are largely absent (Denzin, 2009); AA members are encouraged to promptly admit any relapse and even any urge to relapse. This aspect of AA, combined with the relatively high level of self-reported relapse we observed (i.e., 43\%), suggests that our self-report assessment was at least fairly effective.

A second limitation pertains to our sample; all participants were AA members (at least at Wave 1), and given evidence that AA members differ from alcoholics who are not members of AA (Hurlburt, Gade, \& Fuqua, 1984; Singer, 1997), it remains possible that the relations found here do not generalize to alcoholics who are recovering outside AA. Indeed, Singer (1997) observed that 
some alcoholics feel driven away from AA, primarily because the organization's emphasis on developing a redemptive/self-growth story does not align with their own life experiences. However, redemption has been identified as a major emphasis within Western culture quite broadly, rather than solely within certain recovery programs (McAdams, 2006), so it is likely that the majority of individuals within this cultural context who are seeking to curb a problematic behavioral tendency will be able to resonate with a redemptive-themed life narrative.

A related limitation is the relatively small number of participants who returned for Wave 2 in Study 2 (and the even smaller subsample of these individuals who produced a redemptive narrative at Wave 1). For all of these reasons, one critical future direction is to replicate the present findings using larger samples, ideally from different populations of recovering addicts, recruited from both within and outside AA. Furthermore, given the high attrition rate in Study 2, it is possible that the results of that study would have differed had our entire sample completed the follow-up assessment. This possibility, however, is mitigated by the fact that those participants who did and did not return for Wave 2 did not differ demographically and were comparable on the majority of personality and narrative variables considered. In addition, this dropout rate represents a largely unavoidable repercussion of targeting a highly ecologically valid sample. Many newly sober alcoholics live in flux (e.g., halfway houses), and repeatedly relocate as they attempt to recover from their addiction(s). This makes it difficult to ensure that participants return for multiple assessments of a laboratory-based longitudinal study.

Third, given that alcoholics are not considered "in remission" until they have maintained sobriety for a period of 12 months, another noteworthy limitation of the present research is the relatively brief span of time between the two waves of assessment. Although we captured participants during a period of considerable instability in drinking behavior (evident based on the substantial variability observed in relapse behavior), an important future direction is to examine whether the impact of redemption holds over a longer period of time. In addressing these concerns, researchers may wish to consider redemptive narratives and behavioral change among more stable populations (e.g., university undergraduates). Such studies would also address questions concerning the generalizability of the present effects; whether, for example, the construction of a narrative containing self-redemption promotes behavioral change only for deeply rooted, intransient behavioral problems such as addictive drinking, or whether narrated self-redemption might represent a path toward improvement in a wide variety of less pathological life domains (e.g., academic or relationship success).

Fourth, although our decision to maintain uniformity in the experience narrated (i.e., one's last drink) allowed us to capture individual differences in the tendency to narrate this decidedly negative event as a possible turning point, doing so may have prevented us from capturing other drinking-related events that, for some participants, were turning points but did not correspond to the last drink (e.g., an especially poignant AA meeting sometime after one's last drink). Alternatively, there may be something privileged about the redemptive framing of one's last drink, in particular. This is an important direction for future research; several researchers have noted the benefits and drawbacks of asking participants to narrate the same experience (e.g., King et al., 2000), and in future work researchers should closely consider the simi- larities and differences between these approaches to the assessment of the life story, in both alcoholic and nonalcoholic samples.

Another limitation of this research was our focus on the predictive ability of a single narrative theme: self-redemption. It remains possible that additional narrative themes correspond to the outcome variables considered here. Gergen and Gergen (1983) proposed that personal narratives can take one of three general forms. One such form, the "progressive" narrative, closely aligns with the theme considered here, in describing an individual's improvement over time. In contrast, the "regressive" narrative is thought to describe good things turning bad, as the qualities of the self decline with the passage of time (see also McAdams et al., 2001). Finally, Gergen and Gergen identified positive and negative "stability" narratives in which the perception of the self remains more or less favorable or unfavorable, respectively.

In a manner analogous to the relation found here between selfredemption and positive behavioral change, it is conceivable that regressive and stability narratives are also associated with certain behavioral trajectories and life outcomes. For example, the construction of a regressive narrative might result in the proliferation (rather than mitigation) of problematic behaviors, including excessive drinking and reduced psychological well-being. Consistent with this notion, McAdams et al. (2001) observed that regressive narratives (referred to as "contamination scripts" by this research group) were associated with lower levels of psychological adjustment. In addition, prior research has found that stability narratives - both positive and negative in valence - are similarly associated with reduced psychological adjustment (Dunlop \& Tracy, 2012). In future studies, researchers should examine the prospective behavioral implications of regressive and stability narratives.

A related limitation pertains to the prompt used in the current study. Participants were asked to narrate an unambiguously negative experience (i.e., drinking and feeling bad as a result). Some described this experience as leading to a positive outcome (e.g., becoming stronger, experiencing a renewed motivation), but most did not. Thus, our findings suggest that those who were able to put a positive spin on a negative event evidenced better outcomes (i.e., maintenance of sobriety and improved health) compared to those who narrated a negative event that was not redeemed. What remains unclear, however, is whether it is redemption (i.e., negative event followed by positive personal change) per se that leads to the outcomes examined here, or whether the narration of a positive ending, irrespective of the affective tone inherent in the story's beginning, would have a similar effect. Indeed, recent work by Kray et al. (2010) indicated that thinking counterfactually about an event stimulates increased benefit finding (and, in turn, a greater sense of personal meaning), regardless of whether the event considered is initially negative, neutral, or positive in valence. Addressing this issue is an important future research direction; however, within the domain of behavioral reform (e.g., recovery from addiction), it is questionable whether a happy ending coupled with a happy beginning would have the same motivational impetus as a story of self-redemption. For most individuals seeking to curb problematic behaviors, constructing an overtly positive narrative would run contrary to the nature of their personal experiences (Singer, 1997), making a purely positive story likely to be less authentic. In addition, as Maruna (2001) argued, the redemptive story may be useful for behavioral change because it serves both personal and social functions - that is, it may play a critical role in convincing not only the narrator, but also others, that one has reformed. In this regard, 
a purely positive story describing how one's life changed from being good to being even better would likely be considerably less compelling. Nonetheless, to disentangle the effects of self-redemption from those of happy endings, experimental research is needed to systematically manipulate the beginnings and endings of personal narratives accordingly.

Consistent with Maruna's (2001) emphasis on the personal and social implications of forming a narrative rife with self-redemption (i.e., the potential promise of sustained behavioral change), as a final point it is worth reflecting on the fact that our personal stories are not constructed in a social vacuum. Rather, these stories are "created within a specific situation, by particular individuals, for particular audiences, and to fulfill particular goals" (McLean, Pasupathi, \& Pals, 2007, p. 262). The manner in which the story is told and received carries important implications for subsequent iterations and, ultimately, its internalization (Pasupathi \& Rich, 2005). Although smallscale qualitative investigations have speculated about the processes that promote the construction and maintenance of redemptive stories (e.g., Denzin, 2009; O'Reilly, 1997), additional quantitative studies are needed to test the proposals put forth by Denzin (2009) and others. By coupling our comprehension of how individuals construct and foster redemptive personal stories with studies like the present one, examining the correspondence between redemption and important outcomes, we will eventually develop a more complete understanding of how the stories we tell function to influence the lives we live.

\section{References}

Adler, J. M. (2012). Living into the story: Agency and coherence in a longitudinal study of narrative identity development and mental health over the course of psychotherapy. Journal of Personality and Social Psychology, 102, 367-389. doi:10.1037/a0025289

Adler, J. M., \& Poulin, M. J. (2009). The political is personal: Narrating 9/11 and psychological well-being. Journal of Personality, 77, 903-932. doi:10.1111/j.1467-6494.2009.00569.x

Affleck, G., Tennen, H., Croog, S., \& Levine, S. (1987). Causal attribution, perceived benefits, and morbidity following a heart attack: An eight-year study. Journal of Counseling and Clinical Psychology, 55, 29-35. doi:10.1037/0022-006X.55.1.29

Alcoholics Anonymous World Services. (2001). The big book (4th ed.). New York, NY: Author.

Bauer, J. J., McAdams, D. P., \& Sakaeda, A. R. (2005). Interpreting the good life: Growth memories in the lives of mature, happy people. Journal of Personality and Social Psychology, 88, 203-217. doi: 10.1037/0022-3514.88.1.203

Baumeister, R. F., Stillwell, A., \& Wotman, S. R. (1990). Victim and perpetrator accounts of interpersonal conflict: Autobiographical narratives about anger. Journal of Personality and Social Psychology, 59, 994-1005. doi:10.1037/0022-3514.59.5.994

Bem, D. J. (1972). Self-perception theory. In L. Berkowitz (Ed.), Advances in experimental social psychology (Vol. 6, pp. 1-62). New York, NY: Academic Press.

Bohn, A., \& Berntsen, D. (2008). Life story development in childhood: The development of life story abilities and the acquisition of cultural life scripts from late middle childhood to adolescence. Developmental Psychology, 44, 1135-1147. doi:10.1037/0012-1649.44.4.1135

Bowling, A. (2005). Modes of questionnaire administration can have serious effects on data quality. Journal of Public Health, 27, 281-291. doi:10.1093/pubmed/fdi031

Bruner, J. S. (1990). Acts of meaning. Cambridge, MA: Harvard University Press.
Carver, C. S., \& Antoni, M. H. (2004). Finding benefit in breast cancer during the year after diagnosis predicts better adjustment 5 to 8 years after diagnosis. Health Psychology, 23, 595-598. doi:10.1037/02786133.23.6.595

Carver, C. S., Scheier, M. F., \& Segerstorm, S. C. (2010). Optimism. Clinical Psychology Review, 30, 879-889. doi:10.1016/j.cpr.2010.01.006

Chandler, M. J., Lalonde, C. E., Sokol, B. W., \& Hallett, D. (2003). Personal persistence, identity development, and suicide. Monographs of the Society for Research in Child Development, 68 (2, Serial No. 273). doi:101111/1540-5834.00231

Cole, D. (1992). After great pain: A new life emerges. New York, NY: Summit.

Conway, M. A. (2005). Memory and the self. Journal of Memory and Language, 53, 594-628. doi:10.1016/j.jml.2005.08.005

Davis, C. G., Nolen-Hoeksema, S., \& Larson, J. (1998). Making sense of loss and benefiting from the experience: Two construals of meaning. Journal of Personality and Social Psychology, 75, 561-574. doi: 10.1037/0022-3514.75.2.561

Dawson, D. A., Grant, B. F., Stinson, F. S., Chou, P. S. Huang, B., \& Ruan, W. J. (2005). Recovery from DSM-IV alcohol dependence: United States, 2001-2002. Addiction, 100, 281-292. doi:10.1111/j.1360-0443 2004.00964.x

Del Boca, F. K., \& Darkes, J. (2003). The validity of self-reports of alcohol consumption: State of the science and challenge for research. Addiction, 98, 1-12. doi:10.1046/j.1359-6357.2003.00586.x

Denzin, N. K. (2009). The alcoholic society: Addiction and recovery of the self. New Brunswick, NJ: Transaction.

Derogatis, L. R. (1975). Brief Symptom Inventory. Baltimore, MD: Clinical Psychometric Research.

Diamond, J. (2001). Narrative means to sober ends: Treating addiction and its aftermath. New York, NY: Guilford Press.

Dowd, E. T., Lawson, G. W., \& Petosa, R. (1986). Attributional styles of alcoholics. International Journal of the Addictions, 21, 589-593.

Dunlop, W. L., \& Tracy, J. L. (2012). The autobiography of addiction: Autobiographical reasoning and psychological adjustment in abstinent alcoholics. Memory. Advance online publication. doi:10.1080/09658211 .2012 .713970

Gergen, K. J., \& Gergen, M. M. (1983). Narratives of the self. In K. Scheibe \& T. Sarbin (Eds.), Studies in social identity (pp. 254-273). New York, NY: Praeger.

Giddens, A. (1991). Modernity and self-identity: Self and society in the late-modern age. Stanford, CA: Stanford University Press.

Habermas, T., \& Bluck, S. (2000). Getting a life: The emergence of the life story in adolescence. Psychological Bulletin, 126, 748-769. doi: 10.1037OT033-2909.126.5.741

Hesselbrock, M., Babor, T. F., Hesselbrock, V., Meyer, R. E., \& Workman, K. (1983). "Never believe an alcoholic?" On the validity of self-report measures of alcohol dependence and related constructs. International Journal of the Addictions, 18, 593-609. doi:10.3109/ 10826088309027359

Hunt, W. A., Barnett, L. W., \& Branch, L. G. (1971). Relapse rates in addiction programs. Journal of Clinical Psychology, 27, 455-456. doi: 10.1002/1097-4679(197110)27:4<455::AID-JCLP2270270412>3.0 .CO;2-R

Hurlburt, G., Gade, E., \& Fuqua, D. (1984). Personality differences between Alcoholics Anonymous members and nonmembers. Journal of Studies on Alcohol, 45, 170-171.

King, L. A. (2001). The hard road and the good life: The happy, mature person. Journal of Humanistic Psychology, 41, 51-72. doi:10.1177/ 0022167801411005

King, L. A., Scollon, C. K., Ramsey, C., \& Williams, T. (2000). Stories of life transition: Subjective well-being and ego development in parents of children with Down syndrome. Journal of Research in Personality, 34 509-536. doi:10.1006/jrpe.2000.2285 
Kirshenbaum, A. P., Olsen, D. M., \& Bickel, W. K. (2009). A quantitative review of the ubiquitous relapse curve. Journal of Substance Abuse Treatment, 36, 8-17. doi:10.1016/j.jsat.2008.04.001

Kray, L. J., George, L. G., Liljenquist, K. A., Galinsky, A. D., Tetlock, P. E., \& Roese, N. J. (2010). From what might have been to what must have been: Counterfactual thinking creates meaning. Journal of Personality and Social Psychology, 98, 106-118. doi:10.1037/a0017905

Lefcourt, H. M., Von Baeyer, C. L., Ware, W. E., \& Conx, D. J. (1979). The Multidimensional-Multiattributional Causality Scale: The development of a goal-specific locus of control scale. Canadian Journal of Behavioral Sciences, 11, 286-304. doi:10.1037/h0081598

Lilgendahl, J. P., \& McAdams, D. P. (2011). Constructing stories of self-growth: How individual differences in patterns of autobiographical reasoning relate to well-being in midlife. Journal of Personality, 79, 391-428. doi:10.1111/j.1467-6494.2010.00688.x

Lodi-Smith, J., Geise, A. C., Roberts, B. W., \& Robins, R. W. (2009). Narrating personality change. Journal of Personality and Social Psychology, 96, 679-689. doi:10.1037/a0014611

Maruna, S. (2001). Making good: How ex-convicts reform and rebuild their lives. Washington, DC: American Psychological Association. doi: 10. $1037 / 10430-000$

Matsuba, M. K., \& Walker, L. J. (2005). Young adult moral exemplars: The making of self through stories. Journal of Research on Adolescence, 15, 275-297. doi:10.1111/j.1532-7795.2005.00097.x

McAdams, D. P. (1985). Power and intimacy. New York, NY: Guilford Press.

McAdams, D. P. (1993). The stories we live by: Personal myths and the making of the self. New York, NY: Guilford Press.

McAdams, D. P. (2001). The psychology of life stories. Review of General Psychology, 5, 100-122. doi:10.1037/1089-2680.5.2.100

McAdams, D. P. (2006). The redemptive self: Stories Americans live by. New York, NY: Oxford University Press.

McAdams, D. P. (2011). George W. Bush and the redemptive dream: A psychological portrait. New York, NY: Oxford University Press.

McAdams, D. P., Diamond, A., de St. Aubin, E., \& Mansfield, E. (1997). Stories of commitment: The psychosocial construction of generative lives. Journal of Personality and Social Psychology, 72, 678-694. doi:10.1037/0022-3514.72.3.678

McAdams, D. P., \& Pals, J. L. (2006). A new Big Five: Fundamental principles for an integrative science of personality. American Psychologist, 61, 204-217. doi:10.1037/0003-066X.61.3.204

McAdams, D. P., Reynolds, J., Lewis, M., Patten, A. H., \& Bowman, P. J. (2001). When bad things turn good and good things turn bad: Sequences of redemption and contamination in life narrative and their relation to psychosocial adaptation in midlife adults and in students. Personality and Social Psychology Bulletin, 27, 474-485. doi:10.1177/ 0146167201274008

McLean, K. C. (2008). Stories of the young and the old: Personal continuity and narrative identity. Developmental Psychology, 44, 254-264. doi:10.1037/0012-1649.44.1.254

McLean, K. C., Breen, A. V., \& Fournier, M. A. (2010). Constructing the self in early, middle, and late adolescent boys: Narrative identity, individuation, and well-being. Journal of Research on Adolescence, 20, 166-187. doi:10.1111/j.1532-7795.2009.00633.x

McLean, K. C., \& Mansfield, C. W. (2011). To reason or not to reason? Is autobiographical reasoning always beneficial? New Directions for Child and Adolescent Development, 131, 85-97. doi:10.1002/cd.291

McLean, K. C., Pasupathi, M., \& Pals, J. L. (2007). Selves creating stories creating selves: A process of self-development. Personality and Social Psychology Review, 11, 262-278. doi:10.1177/1088868307301034

McMillen, J. C., Zuravin, S., \& Rideout, G. B. (1995). Perceived benefit from child sexual abuse. Journal of Consulting and Clinical Psychology, 63, 1037-1043. doi:10.1037/0022-006X.63.6.1037
Moos, R. H., \& Moos, B. S. (2006). Rates and predictors of relapse after natural and treated remission from alcohol use disorders. Addiction, 101, 212-222. doi:10.1111/j.1360-0443.2006.01310.x

Nisbett, R. E., \& Wilson, T. D. (1977). Telling more that we can know: Verbal reports on mental processes. Psychological Review, 84, 231-259. doi:10.1037/0033-295X.84.3.231

O'Reilly, E. B. (1997). Sobering tales: Narratives of alcoholism and recovery. Amherst: University of Massachusetts Press.

Pals, J. L. (2006). Narrative identity processing of difficult life experiences: Pathways of personality development and positive selftransformation in adulthood. Journal of Personality, 74, 1079-1110. doi:10.1111/j.1467-6494.2006.00403.x

Pals, J. L., \& McAdams, D. P. (2004). The transformed self: A narrative understanding of posttraumatic growth. Psychological Inquiry, 15, 65-69.

Pasupathi, M., \& Mansour, E. (2006). Adult age differences in autobiographical reasoning in narratives. Developmental Psychology, 42, 798 808. doi:10.1037/0012-1649.42.5.798

Pasupathi, M., Mansour, E., \& Brubaker, J. R. (2007). Developing a life story: Constructing relations between self and experience in autobiographical narratives. Human Development, 50, 85-110. doi:10.1159/ 000100939

Pasupathi, M., \& Rich, B. (2005). Inattentive listening undermines selfverification in personal storytelling. Journal of Personality, 73, 10511086. doi:10.1111/j.1467-6494.2005.00338.x

Pasupathi, M., \& Wainryb, C. (2010). Developing moral agency through narrative. Human Development, 53, 55-80. doi:10.1159/000288208

Pennebaker, J. W., Booth, R. J., \& Francis, M. E. (2007). Linguistic Inquiry and Word Count: LIWC [Computer software]. Austin, TX: LIWC.net.

Pennebaker, J. W., \& Chung, C. K. (2011). Expressive writing: Connections to physical and mental health. In H. S. Friedman (Ed.), Oxford handbook of health psychology (pp. 417-437). New York, NY: Oxford University Press.

Peterson, C. (1991). The meaning and measurement of explanatory style. Psychological Inquiry, 2, 1-10. doi:10.1207/s15327965pli0201_1

Radloff, L. S. (1977). The CES-D scale: A self-report depression scale for research in the general population. Applied Psychological Measurement, 1, 385-401. doi:10.1177/014662167700100306

Revenson, T. A., Wollman, C. A., \& Felton, B. J. (1983). Social supports as stress buffers for adult cancer patients. Psychosomatic Medicine, 45 , 321-331.

Scheier, M. F., Carver, C. S., \& Bridges, M. W. (1994). Distinguishing optimism from neuroticism (and trait anxiety, self-mastery, and selfesteem): A reevaluation of the Life Orientation Test. Journal of Personality and Social Psychology, 67, 1063-1078. doi:10.1037/0022-3514.67.6.1063

Singer, J. A. (1997). Message in a bottle: Stories of men and addiction. New York, NY: Free Press.

Singer, J. A. (2004). Narrative identity and meaning making across the adult lifespan: An introduction. Journal of Personality, 72, 437-460. doi:10.1111/j.0022-3506.2004.00268.x

Skinner, H. A., \& Allen, B. A. (1992). Alcohol dependence syndrome: Measurement and validation. Journal of Abnormal Psychology, 91, 199-209. doi:10.1037/0021-843X.91.3.199

Tedeschi, R. G., \& Calhoun, L. G. (1996). The Posttraumatic Growth Inventory: Measuring the positive legacy of trauma. Journal of Traumatic Stress, 9, 455-471. doi:10.1002/jts.2490090305

Tomkins, S. S. (1987). Script theory. In J. Aronoff, A. I. Rabin, \& R. A. Zucker (Eds.), The emergence of personality (pp. 147-216). New York, NY: Springer.

Tonigan, J. S., Connors, G. J., \& Miller, W. R. (1996). Alcoholics Anonymous Involvement (AAI) scale: Reliability and norms. Psychology of Addictive Behaviors, 10, 75-80. doi:10.1037/0893-164X.10.2.75

Walker, L. J., \& Frimer, J. A. (2007). Moral personality of brave and caring exemplars. Journal of Personality and Social Psychology, 93, 845-860. doi:10.1037/0022-3514.93.5.845 
Walker, L. J., Frimer, J. A., \& Dunlop, W. L. (2010). Varieties of moral personality: Beyond the banality of heroism. Journal of Personality, 78, 907-942. doi:10.1111/j.1467-6494.2010.00637.x

Ware, J. E., \& Sherbourne, C. D. (1992). The MOS 36-item Short-Form Health Survey (SF-36): I. Conceptual framework and item selection. Medical Care, 30, 473-483. doi:10.1097/00005650-199206000-00002

Watson, D., Clark, L. A., \& Tellegen, A. (1988). Development and validation of brief measures of positive and negative affect: The PANAS scales. Journal of Personality and Social Psychology, 54, 1063-1070. doi:10.1037/0022-3514.54.6.1063
Willinger, U., Lenzinger, E., Hornik, K., Fischer, G., Schönbeck, G., Ascauer, H. N., \& Meszaros, K. (2002). Anxiety as a predictor of relapse in detoxified alcohol-dependent patients. Alcohol and Alcoholism, 37, 609-612. doi:10.1093/alcalc/37.6.609

Wilson, T. D. (2002). Strangers to ourselves: Discovering the adaptive unconscious. Cambridge, MA: Harvard University Press.

Received August 6, 2012 Revision received September 28, 2012 Accepted November 13, 2012

\section{Members of Underrepresented Groups: Reviewers for Journal Manuscripts Wanted}

If you are interested in reviewing manuscripts for APA journals, the APA Publications and Communications Board would like to invite your participation. Manuscript reviewers are vital to the publications process. As a reviewer, you would gain valuable experience in publishing. The P\&C Board is particularly interested in encouraging members of underrepresented groups to participate more in this process.

If you are interested in reviewing manuscripts, please write APA Journals at Reviewers@apa.org. Please note the following important points:

- To be selected as a reviewer, you must have published articles in peer-reviewed journals. The experience of publishing provides a reviewer with the basis for preparing a thorough, objective review.

- To be selected, it is critical to be a regular reader of the five to six empirical journals that are most central to the area or journal for which you would like to review. Current knowledge of recently published research provides a reviewer with the knowledge base to evaluate a new submission within the context of existing research.

- To select the appropriate reviewers for each manuscript, the editor needs detailed information. Please include with your letter your vita. In the letter, please identify which APA journal(s) you are interested in, and describe your area of expertise. Be as specific as possible. For example, "social psychology" is not sufficient-you would need to specify "social cognition" or "attitude change" as well.

- Reviewing a manuscript takes time (1-4 hours per manuscript reviewed). If you are selected to review a manuscript, be prepared to invest the necessary time to evaluate the manuscript thoroughly. 